\title{
Evaluation of the volume and volume fraction of the lateral ventricles in the Parkinsonism
}

\author{
Meltem Acar Güdek a*, Amani Elfaki ${ }^{\text {, }}$, Fikri Ozdemir ${ }^{\text {, }}$ Ilkay Camlidag ${ }^{b}$, Emrah Altunsoy $^{a}$, Bunyamin Sahin ${ }^{a}$ \\ ${ }^{a}$ Department of Anatomy, Faculty of Medicine, Ondokuz Mayls University, Samsun, Turkey \\ ${ }^{b}$ Department of Radiology, Faculty of Medicine, Ondokuz Mayı University, Samsun, Turkey \\ ${ }^{c}$ Department of Neurosurgery, Faculty of Medicine, Ondokuz Mayıs University, Samsun, Turkey
}

\section{ARTICLE INFO}

\section{* Correspondence to:}

Meltem Acar Güdek

Deparment of Anatomy,

Faculty of Medicine,

Ondokuz Mayis University, Samsun, Turkey

e-mail: bio.meltemacar@hotmail.com

\section{Keywords:}

Lateral ventricle

Parkinson's disease

Planimetry

Volume fraction

\section{ABSTRACT}

Parkinson's disease (PD) commonly begins in late middle age and the course is slowly progressive. Ventricular enlargement, a nonspecific measure of brain atrophy, has been associated with PD. The aim of this study is to perform the measurements of the cerebral hemispheres and lateral ventricles using magnetic resonance imaging (MRI) in combination with the stereology, to detect structural alterations in the Parkinsonism. 19 controls (9 female; 10 male) and 18 Parkinson's disease ( 8 female; 10 male) were participated. Structural MRI was done for both groups using a Siemens 1.5 Tesla scanner. The DICOM images were analyzed using the Image software. The planimetry technique was done for assessment of the cut surface areas of the coronal sections. The volume and volume fractions of the lateral ventricles were estimated. The mean volumes of the right and left cerebral hemispheres in control and patient groups were $608.96 \mathrm{~cm}^{3}, 606.94 \mathrm{~cm}^{3}$, and $603.41 \mathrm{~cm}^{3}, 604.27 \mathrm{~cm}^{3}$, respectively. The mean volume fractions of the right and left cerebral hemispheres were $50.07 \%, 49.93 \%$ and $49.99 \%, 50.01 \%$, respectively. The volume and volume fraction of the right and left lateral ventricles in control and patient groups were; $12.82 \mathrm{~cm}^{3}, 2.08 \%, 14.76 \mathrm{~cm}^{3}, 2.42 \%$, and $16.75 \mathrm{~cm}^{3}, 2.88 \%, 17.40 \mathrm{~cm}^{3}, 2.98 \%$, respectively. There were no statistically significant differences between the patients and the controls for the volume and volume fraction of the hemispheres and the ventricles $(p \geq 0.05)$, except for the volume fraction of the hemispheres in the females $(p \leq 0.05)$. The significant different in the volume fraction of the right and left cerebral hemispheres between control and patient females, which related to that the women experience more frequent dyskinesia or bad reactions to PD medications. The finding of asymmetrical lateral ventricular enlargement following the same pattern as motor asymmetry in PD.

J. Exp.Clin.Med., 2014; 31:144 